\section{Loving "Mapple Store" but Hating "Sprawl-Mart": A Case Study of Brand Parodies in The Simpsons}

KOME - An International Journal of Pure Communication Inquiry Volume 4 Issue 1, p. 69-83. (C) The Author(s) 2016 Reprints and Permission: kome@komejournal.com

Published by the Hungarian Communication Studies Association DOI: 10.17646/KOME.2016.15

\author{
Fei Qiao ${ }^{1}$, Brandon Chicotsky ${ }^{2}$ and Andrew C. Billings ${ }^{3}$ \\ ${ }^{1}$ The University of Alabama, USA \\ 2 The University of Alabama, USA \\ ${ }^{3}$ The University of Alabama, USA
}

\begin{abstract}
A content analysis of a total of 96 brands and 405 tweets reveal that 1) feature imitation is more frequently employed than theme imitation in brands with parodies in The Simpsons; 2) brands with parodies contain significantly more negative connotations than positive connotations; and 3) audiences have significantly more positive attitudes than negative attitudes toward both fictional brands and defictionalized brands. The findings are mainly consistent with 1) information processing and persuasive theory in communication and 2) brand defictionalization phenomenon in marketing, providing practical suggestions for both television and marketing practitioners. More theoretical and practical implications were further discussed.
\end{abstract}

Keywords: brand parodies, brand imitation, brand attitude, defictionalized brands, popular media

\title{
Introduction: The Simpsons
}

The Simpsons is a cultural icon of television programming; since 1989 it has broadcast nearly 600 episodes (Lascala, 2014). On August 21, 2014, FXX launched The Simpsons Marathon, airing all 552 episodes over a 12-day period (Snierson, 2014). According to Nielsen ratings, this marathon helped FXX move from 49th to third among cable networks, attracting an average of 1.3 million viewers for prime-time episodes (Deerwester, 2014). A survey conducted in 2006 showed that more than 50 percent of Americans were able to name at least two members of The Simpsons family, while only twenty-two percent of them could list one freedom protected by the First Amendment (White \& Holman, 2011). People enjoy watching and talking about The Simpsons, creating all kinds of online fan communities. It has garnered 
five People's Choice Awards, 31 Emmy Awards, and even a star on the Hollywood Walk of Fame (IMDb, 2014).

One apparent reason for the show's fanatical following is that The Simpsons is full of satire (Irwin, Conard, \& Skoble, 2013). As Irwin et al. (2013) stated, "We see layer upon layer of satire, double meanings, allusions to high as well as popular culture, sight gags, parody, and self-referential humor" (p. 1770). Such satire provides in-depth critiques on flaws and faults in American popular culture (Henry, 2007).

The Simpsons also attracts researchers' attention. Several previous studies attempt to explore The Simpsons from various perspectives, including politics (Woodcock, 2008), popular culture (Rhodes, 2001), public entertainment (Holbert, 2005), and philosophy (Irwin et al., 2013). These authors analyze "The Simpsons effect" by placing the show into a broad social and cultural background. However, the studies rarely focused on exploring the features of the show itself. One recurring, highly celebrated (by fanship), and prominent feature of the show is brand parody. An examination of brand parodies in The Simpsons, and the effects of such brands parodies, is a considerably relevant endeavor. Millions of fans are actively engaged in The Simpsons programming and fan communities, and brand values are potentially altered by parody portrayals in the show. Furthermore, this investigation may reveal necessary and unexplored research dimensions of entertainment media's brand parody phenomenon.

In terms of brand parodies, previous studies focused on the effectiveness and scope of marketing strategies (Petty, 2009, 2012), or the scope of intellectual property protection of the brands (Dogan \& Lemley, 2013; Milne, 2013). The studies seldom focused on basic attributes of brand parodies. In addition, few studies attempted to explore audiences' affective responses to brands with parodies. This study fills these gaps by exploring the types of brand parodies and their interpretive intent (i.e., their connotations) in The Simpsons. Furthermore, this research focus includes audiences' attitudes toward both fictional brands and defictionalized brands in The Simpsons.

\section{Literature Review}

This study explores the types of brand parodies and their connotations in The Simpsons, while examining audiences' attitudes toward fictional brands and defictionalized brands. Based on the aforementioned purpose of the study, the literature review includes four parts: types of brand parodies, connotations of brand parodies, attitudes toward fictional brands with parodies, and attitudes toward defictionalized brands.

\section{Types of Brand Parodies}

The word, "parody," was first used by Aristotle in Poetics (Jean, 2011). The term's initial application is described as, "a comic transformation of a literary work, a piece of music or painting, but also a caricature or satire" (Jean, 2011, p. 19). For example, Marcel Duchamp put a moustache on Mona Lisa's face to achieve a parody of Leonardo da Vinci's famous artwork (Jean, 2011; Shearer \& Gould, 2000). This example reveals the major feature of, "parody," as, "imitation," because it comes from comic transformation or satire of a wellknown work.

From the ancient era of Aristotle to today's entertainment era, the custom of using parody is maintained and applied to all different forms of mass communication. In the field of brand advertising, Zinkhan and Johnson (1994), the first two researchers to associate parody with pop culture, defined parody as, "an artistic work that broadly mimics an author's 
characteristic style (and holds it up to ridicule)" (p. III). This point was expanded when Zinkham and Johnson stated that imitation and mockery were the two elements of a successful parody. Thus, "imitation," can be considered an indispensable part of, "parody." Brand parody is a recurring fixture of advertising parody (Jean, 2011). Advertising parody involves a brand's presentation with humorous, exaggerated, or altered meaning. When used, advertising parody assumes that audiences understand the original, or unaltered meaning (Jean, 2011). The most functional application of brand parody is imitation, which includes feature imitation and theme imitation (Van Horen \& Pieters, 2012). Feature imitation refers to the, "direct imitation of distinctive perceptual features such as letters, colors, shapes, and sounds..." (Van Horen \& Pieters, 2012, p. 247). Most feature imitation focuses on creating a, "literal," similarity between a new brand and the existing brand. For example, in The Simpsons, "Mapple store," is the feature imitation (new brand) of, "Apple store," (existing brand); and, "Pest Bye," (new brand) is the feature imitation of, "Best Buy," (existing brand), etc.

Theme imitation refers to the semantic similarity between a new brand and an existing brand subjected to parody, such as similar visual markers and other readily identifiable attributes associated with the new, parodied brand. These attributes are referred to in literature as packaging (Bruce, 1981; Job, Rumiati, \& Lotto, 1992; Van Horen \& Pieters, 2012). Compared with feature imitation, theme imitation is more, "abstract," because it builds the connection of audiences' interpretation of the new brand with the existing brand by creating similar brand environments for consumers. For example, in The Simpsons, the image of, "Krusty Burger," can generate similar brand feelings as, "Burger King," or, "McDonald's"; the image and settings of, "Blockoland," theme park can create similar brand feelings as a, "Legoland," theme park.

Compared with theme imitation, feature imitation offers two advantages for presenting brand associations for viewers. Firstly, feature imitation utilizes prominent brands with an assumed universal or existing recognition; whereby, words of likeness to the existing brand suggest an ease of mockery (e.g. The Simpsons" "Mapple store" is a clear parody of Apple store) (Van Horen \& Pieters, 2012). Feature imitation can be achieved by simply changing the letters in brand names, using same colors, and adopting similar sounds of brand names (Van Horen \& Pieters, 2012). This approach is a quick and effective method to generate parody effects.

The second feature imitation advantage is more straightforward than theme imitation. While theme imitation creates an environment aimed at prompting brand recall, feature imitation provides literal cues, which may be presented through audio and visual elements in media (as is the case with The Simpsons). These cues are designed for instant brand recall. In summary, feature imitation parodies encourage audiences to relate their knowledge of existing brands to a new brand instantly through obvious cues (Finch, 1996). Hence, feature imitation is a simpler and easier way to achieve brand parody effects than theme imitation.

The Simpsons episodes feature many brands that cannot be found in real life (Barnes \& Chryssochoidis, 2010). These brands are referred to as fictional brands in the current study. Referring to literature, the ease by which audiences are assumed to relate existing brands to new brands suggests a programmatic advantage for featuring imitation selection over theme imitation. Thus, the first hypothesis is proposed:

$\mathrm{H}_{1}$ : There will be a greater proportion of The Simpsons' fictional brands using feature imitation than theme imitation. 


\section{Connotations of Brand Parodies}

Based on the definition of, "parody," using satire or irony is a common way to generate parody effects (Jean, 2011; Zinkhan \& Johnson, 1994). The main underlying element in satire or irony is humor (Howard, 2014). In brand parody, humor is achieved by using information incongruently; meaning, "contrasting unexpected information with an existing schema structure" (Jean, 2011; Lee \& Mason, 1999, p. 156). In other words, when audiences compare the seemingly altered, and in some cases outrageous, information delivered by brand parodies with their existing knowledge of well-known brands, laughter is potentially generated. For example, in The Simpsons, "Pest Bye," is the brand parody for, "Best Buy." The existing brand, "Best Buy," is a well-known retail brand associated with technology products, while the fictional brand, "Pest Bye," is shown selling rat poison, which may prompt a humorous response.

The source of brand parodies comes from a perceived outrageous, exaggerated, or altered transformation of the information (Jean, 2011). Sometimes, such parodies involve demeaning or slanderous portrayals. "Brand parody uses disparagement (hostility, derision, aggression, etc.) to reinforce the humor dimension" (Jean, 2011, p. 21). For example, in The Simpsons, the fictional brand, "Sprawl-Mart," is used as the brand parody for, "Wal-Mart." In the show, "Sprawl-Mart," has a terrible working environment, which treats employees as slaves and prohibits their bathroom breaks (SimpsonsWiki, 2014). Such exaggerated information delivered from, "Sprawl-Mart," is potentially perceived as a hostile and aggressive attack on, "Wal-Mart." The Simpsons uses brand parodies to strategically attack well-known brands in order to consistently reach expected humorous effects (Jean, 2011). Thus, the following hypothesis is proposed:

$\mathrm{H}_{2}$ : In The Simpsons, fictional brands with parodies contain more negative connotations than positive connotations.

\section{Attitudes toward Fictional Brands with Parodies}

The concept of brand attitude consists of three components: 1) affective or feeling; 2) cognition or beliefs; and 3) behavioral intent (Assael, 1998; Jean, 2011; Lantos, 2010). The affective or feeling component refers to individuals' emotional feelings toward a brand, which are expressed with statements similar to, "I don't like Wal-Mart" (McLeod, 2014). The cognition component refers to individuals' knowledge toward the brand, which is expressed in statements similar to, "I believe Wal-Mart provides a terrible working environment" (McLeod, 2014). Behavior component refers to how attitude influences the way one behaves, which is expressed with statements similar to, "I will avoid shopping at Wal-Mart" (McLeod, 2014).

These three components are described in literature as, "interrelated, mutually influential and mutually consistent" (Lantos, 2010, p. 504), because consumers need to achieve cognitive consistency (Lantos, 2010). The critical aspect of cognitive consistency is described as, "the valence of the attitude (both direction and strength)," which is, "congruent with the individual's perception of the object-goal relationships" (Awa \& Nwuche, 2010; Scott, 1959, p. 220). For example, if a person values a good working environment, and sees that Wal-Mart provides a terrible working environment, then the individual should dislike Wal-Mart. In other words, the valence of people's cognition is consistent with the valence of their attitudes. 
When such cognitive consistency is applied in the field of brand attitude, it is called "intraattitude consistency" (Lantos, 2010). Consumers tend to maintain such "intra-attitude consistency" because without consistency, cognitive dissonance appears (Awa \& Nwuche, 2010; Lantos, 2010). For consumers, cognitive dissonance is a state of psychological tension and discomfort caused by the inconsistency among "beliefs, feelings and/or actions" (Lantos, 2010 , p. 504). Hence, in order to avoid such psychological discomfort, consumers tend to have similar beliefs and attitudes. Applying this concept to brand parodies in The Simpsons, audiences' cognition toward the fictional brands with parodies should determine their attitude. As stated, fictional brands with parodies tend to have more negative than positive connotations. Therefore, when audiences receive the brand information delivered in The Simpsons, the connotations of such brands are assumed to potentially prompt negative recognitions. This may lead to negative brand attitudes toward those fictional brands. Thus, the following hypothesis is proposed:

$\mathrm{H}_{3}$ : Audiences have more negative than positive attitudes toward the fictional brands with parodies in The Simpsons.

\section{Attitudes toward Defictionalized Brands}

The defictionalized brands refer to "fictional brands that begin in the virtual world and that become defictionalized and appear in the real-world" (Barnes \& Chryssochoidis, 2010, p. 234). The concept of a defictionalized brand is consistent with the concept of a HyperReal fictional brand proposed by Muzellec, Lynn, and Lambkin (2012) as the brand exists in both a fictional environment and in the real world. Put simply, defictionalized brands or HyperReal fictional brands can be bought, purchased, or engaged in the real world marketplace. Such defictionalized or HyperReal fictional brands are mostly inspired by movies or TV shows (Muzellec et al., 2012). For example, The Bubba Gump Shrimp Co., a chain seafood restaurant, comes from the movie Forrest Gump (Muzellec et al., 2012). Duff Beer, one fictional brand in The Simpsons, can be purchased on Amazon.com. The brand is a novelty energy drink in the U.S. and Mexico (Barnes \& Chryssochoidis, 2010). However, not all fictional brands can be defictionalized. There are two main factors that contribute to defictionalizing a fictional brand. First, the brand originates from a popular film/show/game, which is accepted and liked by audiences. Second, audiences have positive beliefs that they are likely to purchase the products (Barnes \& Chryssochoidis, 2010). Furthermore, when audiences have both positive beliefs and cognition toward the show, as well as positive behavioral intention toward the product, the fictional brand could be defictionalized.

Based on balance theory, individuals tend to maintain, "balance," in their cognitive relationships (Heider, 1946; MacKenzie, Lutz, \& Belch, 1986). Heider argues relationships are balanced "if all three are positive in all respects or if two are negative and one positive," which is reflected in the classic P-O-X model (Heider, 1946, p. 110; MacKenzie et al., 1986, p. 132). In terms of analyzing defictionalized brands, the audience (P) has positive beliefs toward the show $(\mathrm{O})$, leading to their positive attitudes toward brands in the show (X). As previously stated, consumers tend to have intra-attitude consistency (Lantos, 2010). The three components in brand attitude are mutually consistent with each other and influence each other (Lantos, 2010). In terms of analyzing defictionalized brands, positive purchase intention (behavioral component) is consistent with positive beliefs (cognitive component) and feelings (affective component) toward the brands. Therefore, audiences should have positive attitudes toward the brand when the following is present: (a) the brand applies to defictionalized brands in The Simpsons; (b) audiences have positive beliefs toward the show; and (c) 
audiences have positive purchase intention to buy the brand. Thus, the following hypothesis is proposed:

$\mathrm{H}_{4}$ : Audiences have more positive than negative attitudes toward the defictionalized brands in The Simpsons.

\section{Method}

Content analysis is employed in this study. Based on the purpose of the study, the analysis contains two parts: fictional brands and audiences responses.

\section{Sampling}

For fictional brands, the researchers refer to the brands listed under the, "brand parodies," section of The Simpsons Wiki site. The site attracts The Simpsons' fans, who continuously update the site. The Wiki site offers retrievable, archived content and a comprehensive database of The Simpsons information. This resource provides an extensive list of all the brands parodied in the show. All brand information was retrieved by October 31, 2014.

For audiences' responses to fictional brands, the researchers refer to Twitter as the platform where brand attitudes are expressed. The reason for including Twitter, a social media platform, in the study is because it has 271 million active users per month (Twitter, 2014); which means Twitter has become one of the largest social media communities in the world. Twitter has also become one of the most commonly used tools for people to communicate with others. All users can hashtag keywords, which tags terms for retrievable searches, enabling researchers to keep track of users' online information. For fictional brands, the unit of analysis was each brand. For audiences' responses, the unit of analysis was each tweet. All relevant tweets were collected by October 31, 2014.

\section{Coding Procedure and Intercoder Reliability}

For fictional brands, the researchers code all the brands on the list provided by The Simpsons Wiki in the, "brand parodies," section. There are 96 fictional brands with parodies provided. For audiences' responses, the coders first use, "\#brand name," to search all fictional brands on the brand list via Twitter's official search engine and Topsy.com-a Twitter-certified social search engine. Then, the coders code all tweets containing that specific brand name. There are two coders. The two coders code $15 \%$ of all items together. Using Cohen's kappa analysis, the overall intercoder reliability is .881 , indicating two coders have substantial agreement on measured variables (Landis \& Koch, 1977).

\section{Measured Variables}

Imitation. On The Simpsons Wiki list, all brand parodies come with an image clipped from the original episode. The coders use these images to determine whether it is a feature imitation or theme imitation. If it is a feature imitation, the numerical assignment of 1 is applied. If it is a theme imitation, the numerical assignment of 2 is applied. For imitation variable, the intercoder reliability is 1.0 , indicating high agreement on the imitation variable.

Connotation. On The Simpsons Wiki list, all brand parodies come with hyperlinks. After clicking on the hyperlink, there is a description about how and when this 
brand appears in the episode. If the description is negative, the numerical assignment of 1 is applied. If it is positive, the numerical assignment of 2 is applied. If it is neutral, the numerical assignment of 3 is applied. For the coding schema, "negative" refers to the description explicitly depicting the negative details of the brand. For example, for "SprawlMart" The Simpsons Wiki site depicted "Sprawl-Mart" as a terrible place to work. A description example is, "It literally treats its employees like slaves..." (The Simpsons Wiki Site). In this case, this brand parody is coded as negative. "Positive" refers to the description explicitly depicting the positive details of the brand. For example, "Duff Beer" is described as "Duff Beer is the most popular brand of beer in Springfield. It is Homer Simpson's favorite drink..." (The Simpsons Wiki Site) In this case, the statement is coded as positive. "Neutral" refers to a description with both negative and positive details provided on the The Simpsons Wiki site's "brand parodies" section. For the connotation variable, the intercoder reliability was .710.

Attitudes toward Fictional Brands. The current study uses NET method to code attitude toward the fictional brands (Van Cuilenburg, Kleinnijenhuis, \& De Ridder, 1988). This method is a textual analysis method and has been used to analyze content on varying platforms. This method is employed to focus on, "core phrases," to measure the valence of audiences' responses (Willemsen, Neijens, Bronner, \& de Ridder, 2011). A core phrase refers to the subject, predicate, and object of a statement on behalf of fictional brands. The researchers utilize NET method to analyze the valence of the expressed attitudes by those tweeting about fictional brands. The positive affective valence refers to the linkage of the new brand with the existing brand. For existing brands, subjective expressions like good, impressive, essential, etc. are factored. For example, if one tweet is, "\#Mapple store, it's a fun place," then, the core phrase is, "Mapple store is a fun place." According to dictionary.com, "fun," means enjoyment or playfulness; whereby, the researchers can reasonably assume a positive attitude is expressed for the, "Mapple Store." Therefore, this tweet is coded as, "positive."

On the other hand, the negative valence refers to the linkage of the parodied brand with the existing brand, with subjective expressions like bad, unimpressive, nonessential, etc. For example, if one tweet is, "\#Sprawl-Mart, terrible place," then, the core phrase was, "SprawlMart is a terrible place." Therefore, this tweet is coded as a, "negative," attitude toward, "Sprawl-Mart." If there is no affective description for the brand, then it is coded as, "neutral." For attitudes toward fictional brands with parodies, the intercoder reliability was .719.

Attitudes toward Defictionalized Brands. The coders select tweets, which talk about real products based on two criteria. First, if tweets have a photo of a real product it is selected. For example, if one tweet is, "\#Krusty Burger is amazing," with a photo of the user holding a Krusty burger, then this tweet qualifies. Second, if tweets explicitly express users' consumption of the products, it is selected. For example, if the tweet states, "I'm eating Krusty burger at Orlando, it tastes good!" then this tweet qualifies. If the tweet is written as, "\#Krusty Burger in The Simpsons looks terrible," and the tweet does not have a picture of the real product, or fails to show any evidence that this user is consuming the real burger, then this tweet is disqualified.

In terms of analyzing affective valence, the same NET method is applied. For attitude toward defictionalized brands, the intercoder reliability was .795. 


\section{Results}

The present study analyzes 96 brands with parodies in The Simpsons. A total of 406 relative and retrievable tweets posted before October 31, 2014 are analyzed. Each hypothesis focuses on comparing the proportions of variables in one theoretical concept. Thus, a series of nonparametric binomial tests are conducted.

Table 1: Non-parametric Binomial Test Results

\begin{tabular}{|c|c|c|c|c|}
\hline Variables & & $\mathbf{N}$ & Proportion & Sig \\
\hline \multirow{2}{*}{ Imitation } & $\begin{array}{l}\text { Feature } \\
\text { Imitation }\end{array}$ & 63 & 66 & \multirow{2}{*}{.003} \\
\hline & $\begin{array}{l}\text { Theme } \\
\text { Imitation }\end{array}$ & 33 & 34 & \\
\hline \multirow{2}{*}{ Connotation } & Positive & 1 & 4 & \multirow{2}{*}{.000} \\
\hline & Negative & 26 & 96 & \\
\hline \multirow{2}{*}{ Attitude toward fictional brands } & Positive & 77 & 61 & \multirow{2}{*}{.016} \\
\hline & Negative & 49 & 39 & \\
\hline \multirow{2}{*}{ Attitude toward defictionalized brands } & Positive & 260 & 97 & \multirow{2}{*}{.000} \\
\hline & Negative & 9 & 3 & \\
\hline
\end{tabular}

H1 examines the use of feature and theme imitation among the fictional brands with parodies. According to the binomial tests, the proportion of feature imitation is $66 \%(N=63)$ and the proportion of theme imitation is $34 \%(N=33)$. The $p$ value is .003 , which is less than .05 , indicating that the usage of feature imitation is significantly greater than the usage of theme imitation. Therefore, $\mathrm{H} 1$ is supported.

$\mathrm{H} 2$ explores the connotation in the fictional brands with parodies. Of all the fictional brands with parodies, there are 27 brand parodies that contain either negative or positive connotations. Based on the test, the proportion containing negative connotations in fictional brands with parodies is $96 \%(N=26)$, and the proportion containing positive connotations is $4 \%(N=1)$. The $p$ value is .000 , which is less than .05 , indicating that brands with negative connotations are significantly greater than brands with positive connotations. Therefore, $\mathrm{H} 2$ is supported.

H3 explores the valence of audiences' attitudes toward fictional brands with parodies. A total of 18 fictional brands are found from keywords on Twitter. All 132 tweets about these 18 fictional brands are analyzed. Of all 132 tweets, there are 126 tweets that explicitly express users' positive and negative attitudes. All 18 brands considered in this study have multiple tweets. For the purposes of this study, tweets are only analyzed if they associate, express, or describe one brand. According to the test results, the proportion of positive attitude toward fictional brands in The Simpsons is $61 \%(N=77)$, and the proportion of negative attitude is $39 \%(N=49)$. The $p$ value is .016 , which is less than .05 , indicating that audiences have 
significantly more positive attitudes toward fictional brands than negative attitudes. Therefore, H3 is not supported.

H4 examines the valence of audiences' attitudes toward defictionalized brands in The Simpsons. A total of eight defictionalized brands are found from keywords on Twitter. For the purposes of this study, tweets are only analyzed if they associate, express, or describe one brand. All 274 tweets about these eight defictionalized brands are analyzed. Of all 274 tweets, there are 269 tweets that explicitly express users' positive and negative attitudes. All eight brands considered in this study have multiple tweets. Based on the test results, the proportion of positive attitudes is $97 \%(N=260)$, and the proportion of negative attitudes is $3 \%(N=9)$. The $p$ value is .000 , which is less than .05 , showing that audiences have significantly more positive attitudes toward the defictionalized brands than negative attitudes. Therefore, H4 is supported.

Table 2: Tweets of Fictional brands with Parodies Dispersion Table

\begin{tabular}{|l|c|c|c|}
\hline Brand Names & N & Percent & Median \\
\hline Abosulut Krusty & 9 & $6.8 \%$ & 2.00 \\
\hline Barely Regal Magazine & 1 & $.75 \%$ & 2.00 \\
\hline Duff Beer & 2 & $1.5 \%$ & 2.00 \\
\hline Blocko Store & 5 & $3.8 \%$ & 2.00 \\
\hline Blockoland & 8 & $6.0 \%$ & 2.00 \\
\hline Blood bath \& beyond gun shop & 2 & $1.5 \%$ & 1.00 \\
\hline Diz-nee-land & 4 & $3.0 \%$ & 2.00 \\
\hline Funtendo Zii & 9 & $6.8 \%$ & 2.00 \\
\hline Kentucky Fried Panda & 9 & $6.8 \%$ & 1.00 \\
\hline Krusty Burger & 1 & $.75 \%$ & 2.00 \\
\hline Lard Lad & 3 & $2.2 \%$ & 1.00 \\
\hline Mapple Store & 15 & $11.3 \%$ & 2.00 \\
\hline Sprawl-Mart & 32 & $24.2 \%$ & 1.00 \\
\hline Super star Celebrity Microphone & 1 & $.75 \%$ & 1.00 \\
\hline Wall E. Weasel's & 10 & $7.5 \%$ & 2.00 \\
\hline Victor's Secret & 10 & $7.5 \%$ & 2.00 \\
\hline World of Krust Craft & 1 & $.75 \%$ & 1.00 \\
\hline Lamborgotti & 10 & $7.5 \%$ & 2.00 \\
\hline Total N & $\mathbf{1 3 2}$ & & \\
\hline
\end{tabular}


Table 3: Tweets of Defictionalized brands Dispersion Table

\begin{tabular}{|l|c|c|c|}
\hline Brand Names & N & Percent & Median \\
\hline Abosolut Krusty & 1 & $.36 \%$ & 2.00 \\
\hline Buzz Cola & 65 & $23.7 \%$ & 2.00 \\
\hline Blocko Store & 3 & $1.1 \%$ & 2.00 \\
\hline Krusty Burger & 72 & $26 \%$ & 2.00 \\
\hline Lard Lad & 62 & $22.6 \%$ & 2.00 \\
\hline Duff Beer & 69 & $25.1 \%$ & 2.00 \\
\hline Kentucky Fried Panda & 1 & $.36 \%$ & 2.00 \\
\hline World of Krust Craft & 1 & $.36 \%$ & 2.00 \\
\hline Total N & $\mathbf{2 7 4}$ & & \\
\hline
\end{tabular}

\section{Discussion}

By conducting a case study on brand parodies in The Simpsons, this research examines imitation and connotation, as well as audiences' attitudes toward fictional and defictionalized brands in The Simpsons. The results reveal that feature imitation is applied more frequently than theme imitation for brand parodies, and brand parodies contain more negative connotations than positive connotations. Furthermore, audiences have more positive attitudes than negative attitudes toward both fictional and defictionalized brands in The Simpsons. Based on these findings, the researchers present potentially significant theoretical and practical implications.

\section{Theoretical and Practical Implications}

One notable result of this study is that audiences have significantly more positive than negative attitudes toward fictional brands in The Simpsons. This result is an opposite outcome from the hypothesis. Two explanations may include considerations of audience expressions on social media and the functions of brand parodies, which include serious attacks and playful wit. The first consideration focuses on audiences who express critical and negative attitudes toward real brands on social media by referring to fictional brands that parody the brand under ridicule. In other words, audiences are associating fictional brands with existing brands and are voicing their attitudes about real brands by reacting to fictional brands. For example, "Mapple Store," is the brand parody for, "Apple Store." Meanwhile, The Simpsons is sponsored by Microsoft (Barnett, 2010). Therefore, "Mapple Store," may have a rather negative brand connotation from the perspective of the writers of the show, as Microsoft and Apple are competitive brands. However, on Twitter, audiences expressed more positive than negative attitudes toward, "Mapple Store," which might reflect their real attitudes toward, "Apple Store." On the other hand, "Sprawl-Mart," a brand parody for, "Wal-Mart," also has a negative connotation in The Simpsons. Unlike, "Mapple Store," the audiences have more negative than positive attitudes toward, "Sprawl-Mart," which might indicate their existing attitudes toward "Wal-Mart." Therefore, audiences' prior brand attitudes play an important role in their attitudes toward fictional brands in The Simpsons. Such prior brand attitude cannot be easily changed because it is formed by brand beliefs, feelings, and actual purchase 
experience (Awa \& Nwuche, 2010). Based on information processing and persuasion theory, when encountering a new message, individuals tend to retrieve prior knowledge and experiences from their memory. Such prior beliefs and experiences represent a, "highly valid, trustworthy source of information," for individuals (Wood, Kallgren, \& Preisler, 1985, p. 74). Individuals cannot be easily persuaded by a new message because they perceive their prior knowledge as a highly credible information source. Hence, applying this theory to the current study suggests audiences tend not to accept the negative connotation delivered by brand parodies in The Simpsons when those negative messages are inconsistent with their prior knowledge. Therefore, negative connotations of brand parodies might not necessarily influence audiences' attitudes toward fictional brands.

Gary (2006) believes that The Simpsons' logic of using television is opposite other television genres. According to Caughie (1990), television is considered an "interrupted or interruptible space, a space of continual intertextual collisions, and of lexial fragmentation and juxtaposition" (see Gary, 2006, p. 93). Animated programs that incorporate parodies, such as The Simpsons, take advantage of this system of television, attempting to utilize television against advertisers and cause the collisions of intertexual, cultural and societal meanings of the advertisers or brands (Gary, 2006). Also, Gary (2006) proposes that the interaction between the entertainment show and the public sphere is actually a way of communicating the values of the show. For example, the negative connotation of, "Sprawl-Mart," in The Simpsons reflects the show's negative attitude toward Wal-Mart. When using brand parodies, negative connotations are often attached to existing brands, which is helpful to achieve desired satire effects. However, in terms of the public sphere, such negative connotations might not persuade audiences to change their perceptions toward existing brands because, if audiences' prior brand beliefs are not consistent with the messages delivered by brand parodies, audiences might not change their brand attitudes toward existing brands (Wood et al., 1985). Hence, if producers and writers intend to incorporate brand parody, they may benefit from careful planning, caution, and tact.

Moreover, there is another potential explanation stemming from the functions of brand parodies. Brand parodies use disparaging humor to serve two functions: serious attack and playful wit (Bergh et al., 2011). If brand parodies serve the purpose of serious attacks, then the existing brands become the targets of such brand parodies; whereby, audiences expect the existing brands to be attacked or harmed (Bergh et al., 2011). If the use of brand parodies is to achieve playful wit, then such brand parodies would pay homage to the existing brands, because the humor in brand parodies serves to create a delightful emotional connection with the existing brands. It is important to note that audiences tend to have rather positive attitudes toward this kind of brand parody (Bergh et al., 2011). This study considers how audiences might perceive brand parodies in The Simpsons as playful wit for the existing brand because the show is positioned as an adult animated sitcom. Based on the theoretical framework and current study, the researchers can logically assume audiences enjoy the pleasant brand association, explaining why audiences have more positive than negative attitudes toward fictional brands in The Simpsons.

The results also show that feature imitation is used more frequently than theme imitation for brand parodies. As noted previously, feature imitation could be perceived as a more straightforward method to achieve brand parody. Therefore, when considering adopting parody as a brand strategy, using feature imitation is potentially more effective for delivering outrageous, exaggerated, or altered brand information to audiences by attacking existing brands in a direct manner.

Finally, this study presents evidence that audiences have significantly more positive than negative attitudes toward defictionalized brands. This significant finding is in line with balance theory and intra-attitude consistency. For future considerations, researchers may find 
fruitful investigations in audiences' positive perceptions toward The Simpsons and audiences' positive purchase intentions, as they may generate positive attitudes toward defictionalized brands in the show (Barnes \& Chryssochoidis, 2010). The current study's findings are consistent with the model of brand defictionalization proposed by Barnes (2010). According to the model, media is one of the three major issues that influence consumers' attitudes toward defictionalized brands. If audiences have positive perception toward a film, enjoy the film, and accept the content of the film, then audiences may tend to have positive brand attitudes toward defictionalized brands in the film. The current study's results support this behavioral and attitudinal concept demonstrated in the model of brand defictionalization.

This significant finding indicates that popular culture can exert great impact on marketing strategies. If one show is widely accepted and liked by the public, then the fictional brands in that show are potentially of great value. If those fictional brands are defictionalized then the public may have positive attitudes toward them and potentially purchase those products. This may lead to increased economic profits, consistent with reverse product placement marketing phenomena (Muzellec et al., 2012). According to Edery (2006), reversed product placement is defined as "creating a fictional brand in a fictional environment and then placing it into the real world" (Muzellec et al., 2012, p. 819). Only when the HyperReal brands are tangible in the real marketplace can the economic value of the brands be realized. As a result, popular television shows or films serve as salient vehicles for adopting defictionalizing brand marketing strategies.

\section{Limitations and Future Considerations}

The current study employs content analysis as the method to examine the hypotheses presented. Content analysis provides a direct, descriptive analysis of the variables, but it cannot explicate the thoughts and perceptions of audiences. Therefore, in future studies, survey method is suggested to explore more in depth how audiences feel, perceive, and evaluate both fictional and defictionalized brands.

Survey method included in an investigation that addresses feelings, ideas, reflections, perceptions, sensitivities, and other intangible expressions by respondents, might better define the universe in which brand parodies are viewed and internalized by audiences. For example, Muzellec, Kanitz and Lynn (2013) used survey to examine individuals' (a) perceived service quality; (b) attitude toward different television shows; (c) identification with the fictional service brands; (d) attitude toward the fictional service brand; and (e) their purchase intention of the fictional service brands, providing solid foundation of exploring an in-depth relationship between consumers' attitudinal influences on their purchase intention of fictional brands. Therefore, a future study employing the survey method may better determine whether attitudes toward brands with parodies serve as a surrogate of existing brands. In other words, researchers may factor whether a percentage of negative responses about, "Sprawl-Mart," for example, function as a mirrored percentage of negativity toward WalMart. If so, parodies may provide useful heuristics for existing brands without having to directly test existing brands. Moreover, if researchers or businesses intend to explore multiple avenues for testing audiences' attitudes, they may test audiences' attitudes toward existing brands and brand parodies to generate valuable data sets for insightful comparisons.

The current study uses NET analysis to investigate audiences' attitudes. Willemsen et al. (2011) stated that NET analysis might not have high accuracy because it is based on coders' subjective judgment. Although the intercoder reliability for both fictional and defictionalized brands in the current study are relatively high, with Cohen's Kappa of .719 and .795 respectively, this analysis still needs to be further developed. In future studies, it is suggested 
that different analysis methods are used to examine valence of attitudes to increase the measure of accuracy. Even though the current study attempts to investigate all retrievable tweets posted before October 31,2014 , the sample size is relatively small; future studies should seek to incorporate, more samples from different social media platforms.

Lastly, the current study only focuses on brand parodies in The Simpsons, which is an adult animated sitcom. The Simpsons tends to, "incorporate queer characters and queer themes" (Pinsky, 2001, p. 2), which is meant to explain the playfulness of the show. The themes presented in the show might influence the use of parody strategy and the connotations of brands showcased. Therefore, the researchers suggest more shows of different genres are evaluated to add to the initial evaluation presented herein.

\section{Conclusion}

In one episode of The Simpsons, Sideshow Bob, a common character in the show, attempts to use a nuclear bomb to destroy all televisions in Springfield (the show's main plot setting). The dialogue offered a notable point by the character, Krusty, by stating, "Would it really be worth living in a world without television? I think the survivors would envy the dead" (Delaney, 2007). It is possible many people are inclined to agree with Krusty that a world is less desirable without television. It is even harder to "imagine a world without popular culture" (Delaney, 2007, p. 1). Popular television shows are the main source of forming popular culture (Delaney, 2007). The Simpsons is representative of such popular culture that originates from popular television shows. Through a case study of brand parodies in The Simpsons, the current research examines the attributes and connotations of The Simpsons' fictional brands, as well as audiences' affective responses toward The Simpsons' fictional and defictionalized brands. The study adds a new dimension to the research exploring The Simpsons phenomenon, providing a better understanding of the influence of media within popular culture.

\section{References}

Assael, H. (1998). Consumer behavior and marketing action. Cincinnati, OH: South-Western College Publishing.

Awa, H. O., \& Nwuche, C. A. (2010). Cognitive consistency in purchase behavior: Theoretical \& empirical analyses. International Journal of Psychological Studies, 2(1), 44-54. CrossRef

Barnes, S. J., \& Chryssochoidis, G. (2010). From fiction to fact: Exploring the defictionalization of brands in media. In: 2010 AMA Educators' Proceedings 'Enhancing Knowledge Development in Marketing', 2010-08-01, Boston. pp. 230-239.

Barnett, E. (2010). Microsoft's bing sponsors 'The Simpsons'. Retrieved from http://www.telegraph.co.uk/technology/microsoft/7422320/Microsofts-Bing-sponsorsThe-Simpsons.html [last accessed on the $24^{\text {th }}$ May, 2016]

Bergh, B. V., Lee, M., Quilliam, E. T., \& Hove, T. (2011). The multidimensional nature and brand impact of user-generated ad parodies in social media. International Journal of Advertising, 30(1), 103-131. CrossRef

Bruce, V. (1981). Visual and semantic effects in a serial word classification task. Current Psychological Research, 1(3-4), 153-161. 
Deerwester, J. (2014). Nielsen ratings: 'Simpsons' marathon, Emmy Awards. Retrieved from http://www.usatoday.com/story/life/tv/2014/09/03/nielsen-chatter-week-ending-0831/15023061/ [last accessed on the $24^{\text {th }}$ May, 2016]

Delaney, T. (2007). Pop Culture: An overview. Retrieved from: https://philosophynow.org/issues/64/Pop_Culture_An_Overview [last accessed on the $24^{\text {th }}$ May, 2016]

Dogan, S. L., \& Lemley, M. A. (2013). Parody as Brand. UC Davis Law Review, 47, 473969.

Edery, D. (2006). Reverse product placement in virtual worlds. Harvard Business Review, 84(12), 24-24.

Finch, A. C. (1996). When imitation is the sincerest form of flattery: Private label products and the role of intention in determining trade dress infringement. University of Chicago Law Review, 63(3), 1243-1276

Gary, J. (2006). Watching the Simpsons: $t v$, parody and intertextuality. New York: Routledge .

Heider, F. (1946). Attitudes and cognitive organization. The Journal of Psychology, 21(1), 107-112.

Henry, M. (2007). "Don't ask me, I'm just a girl": Feminism, female identity, and 'The Simpsons'. The Journal of Popular Culture, 40(2), 272-303.

Holbert, R. L. (2005). A typology for the study of entertainment television and politics. American Behavioral Scientist, 49(3), 436-453. CrossRef

Howard, M. (2014). Satire, parody, or spoof: Types of humorous writing. [Lesson Transcript] Retrieved from http://study.com/academy/lesson/satire-parody-or-spoof-types-ofhumorous-writing.html [last accessed on the $24^{\text {th }}$ May, 2016]

IMDb. (2014). The Simpsons. Retrieved from http://www.imdb.com/title/tt0096697/awards [last accessed on the $24^{\text {th }}$ May, 2016]

Irwin, W., Conard, M. T., \& Skoble, A. J. (eds.) (2013). The Simpsons and Philosophy: The D'oh! of Homer (Vol. 2) Chicago and La Salle: Open Court.

Jean, S. (2011). Brand parody: a communication strategy to attack a competitor. Journal of Consumer Marketing, 28(1), 19-26. CrossRef

Job, R., Rumiati, R., \& Lotto, L. (1992). The picture superiority effect in categorization: visual or semantic? Journal of Experimental Psychology: Learning, Memory, and Cognition, 18(5), 1019-1028. CrossRef

Landis, J. R., \& Koch, G. G. (1977). The measurement of observer agreement for categorical data. Biometrics, 159-174.

Lantos, G. P. (2010). Consumer behavior in action: Real-life applications for marketing managers. Armonk: M.E. Sharpe

Lascala, M. (2014). How many seasons of "The Simpsons" are there? Just know the show has been on forever. Retrieved from http://www.bustle.com/articles/41530-how-manyseasons-of-the-simpsons-are-there-just-know-the-show-has-been-on-for-ever [last accessed on the $24^{\text {th }}$ May, 2016]

Lee, Y. H., \& Mason, C. (1999). Responses to information incongruency in advertising: The role of expectancy, relevancy, and humor. Journal of Consumer Research, 26(2), 156169. CrossRef

MacKenzie, S. B., Lutz, R. J., \& Belch, G. E. (1986). The role of attitude toward the ad as a mediator of advertising effectiveness: A Test of Competing Explanations. Journal of Marketing Research, 23(2), 130-143. CrossRef

McLeod, S. (2014). Attitudes and behavior. Retrieved from: http://www.simplypsychology.org/attitudes.html [last accessed on the $24^{\text {th }}$ May, 2016] 
Milne, E. (2013). Parody: Affective registers, amateur aesthetics and intellectual property. Cultural Studies Review, 19(1), 193-215. CrossRef

Muzellec, L., Lynn, T., \& Lambkin, M. (2012). Branding in fictional and virtual environments: Introducing a new conceptual domain and research agenda. European Journal of Marketing, 46(6), 811-826. $\underline{\text { CrossRef }}$

Muzellec, L., Kanitz, C., \& Lynn, T. (2013). Fancy a coffee with Friends in 'Central Perk'? Reverse product placement, fictional brands and purchase intention. International Journal of Advertising, 32(3), 399-417. CrossRef

Petty, R. D. (2009). Brand parody products: Is the harm worth the howl? Journal of Consumer Marketing, 26(2), 64-65. CrossRef

Petty, R. D. (2012). Using the law to protect the brand on social media sites: A three "M" $\mathrm{s}$ framework for marketing managers. Management Research Review, 35(9), 758-769. CrossRef

Pinsky, M. I. (2001). The Gospel according to the Simpsons: The spiritual life of the world's most animated family. Westminster: John Knox Press.

Rhodes, C. (2001). D'oh. The Simpsons, popular culture, and the organizational carnival. Journal of Management Inquiry, 10(4), 374-383. CrossRef

Scott, W. A. (1959). Cognitive consistency, response reinforcement, and attitude change. Sociometry, 22(3), 219-229

Shearer, R., \& Gould, S. (2000). The 1919 and 1930 versions of Marcel Duchamp's series of images of the Mona Lisa with a moustache and beard, entitled L.H.O.O.Q., prove a source of confusion. Retrieved from:

http://www.duchamp.org/symposium/article1letter.html [last accessed on the $24^{\text {th }}$ May, 2016]

SimpsonsWiki. (2014). Sprawl-Mart, from http://simpsons.wikia.com/wiki/Sprawl-Mart [last accessed on the $24^{\text {th }}$ May, 2016]

Snierson, D. (2014). 'The Simpsons': FXX to air every episode in 12-day marathon. Retrieved from http://insidetv.ew.com/2014/04/09/fxx-simpsons-marathon/ [last accessed on the $24^{\text {th }}$ May, 2016]

Twitter. (2014). About. Retrieved from https://about.twitter.com/company [last accessed on the $24^{\text {th }}$ May, 2016]

Van Cuilenburg, J. J., Kleinnijenhuis, J., \& De Ridder, J. A. (1988). Artificial intelligence and content analysis. Problems of and strategies for computer text analysis. Quality and Quantity, 22(1), 65-97. CrossRef

Van Horen, F., \& Pieters, R. (2012). Consumer evaluation of copycat brands: The effect of imitation type. International Journal of Research in Marketing, 29(3), 246-255. CrossRef

White, K. M., \& Holman, M. (2011). Pop culture, politics, and America's favorite animated family: Partisan bias in 'The Simpsons'? Studies in Popular Culture 34(1), 87-107.

Willemsen, L. M., Neijens, P. C., Bronner, F., \& de Ridder, J. A. (2011). "Highly recommended!" The content characteristics and perceived usefulness of online consumer reviews. Journal of Computer-Mediated Communication, 17(1), 19-38. CrossRef

Wood, W., Kallgren, C. A., \& Preisler, R. M. (1985). Access to attitude-relevant information in memory as a determinant of persuasion: The role of message attributes. Journal of Experimental Social Psychology, 21(1), 73-85. CrossRef

Woodcock, P. (2008). Gender, politicians and public health: using 'The Simpsons' to teach politics. European Political Science, 7(2), 153-164. CrossRef

Zinkhan, G. M., \& Johnson, M. (1994). From the Editor: The use of parody in advertising, Editorial, Journal of Advertising 23(3), III-VIII. 